\title{
The Design of Innovative Complaint Systems Inside University to Face Globalization
}

\author{
Titien. S. Sukamto ${ }^{1}$, Indra Gamayanto ${ }^{1} \&$ Sasono Wibowo $^{1}$ \\ ${ }^{1}$ Department of Information Systems, Dian Nuswantoro University, Semarang, Indonesia \\ Correspondence: Titien S. Sukamto, Faculty of Computer Science, Department Of Information Systems, Dian \\ Nuswantoro University (UDINUS), Semarang, Imam Bonjol Street No. 207, Semarang, 24-351-7261. Fax: 24- \\ 356-9684. E-mail: titien.suhartini@dsn.dinus.ac.id
}

Received: June 15, 2018; Accepted: July 4, 2018; Published: August 20, 2018

The research is financed by ATEK FOODS - Suppliers.

\begin{abstract}
One of the most important pillars that we must address in the ASEAN Economic Community (AEC) is to develop a good management process at University in Indonesia, one of the most important part is complaint management. Complaint management should get more attention from the University, because these factors tend to bring the campus atmosphere to become more conducive and to solve some communication problems between and/or among lecturers and students. In this paper, we will proposed a complaint management framework in order to solve the problems of complaints, especially at the university level. The proposed method are adopted from complaint methods that already be used in Northumbria University, England, and Australian International College, then it will be cutomized with the management and education process, and also cultural behaviour at universities in Indonesia. This framework will help us to solve the complaint problems objectively and fairly, so that both sides can feel comfortable while running the learning/education process on campus. Furthermore, this will be linked to four important things that will result in a solution to improve service at the university level, so that all universities in Indonesia will be able to improve the complaint process more effectively and efficiently.
\end{abstract}

Keywords: complaint, university, lecturer, systems, innovations

\section{Introduction}

The Development of Information Technology and Information Systems grew very rapidly in the era of the ASEAN Economic Community (AEC) and/or Globalization; Indonesia would have to prepare to face it. Therefore, one of the things that need to be very aware of is input, opinions, and proper judgment in a case and/or something. For example, in many cases, complaint that occurs at the university level is not handled properly, so that it can create an ongoing misunderstanding, this due to the absence of a joint solution or less objective in looking at the case. This paper will put our knowledge, observation, judgment, experience and create a framework that could be implemented in University. With respect and honor to the system at any university that has been made and implemented till now, a framework created so that can be used for all situations, by adapting to the existing system and cultural behavior of the University.

First of all, we will give you the results of our analysis of the existing complaints system now, we might just take a few examples of existing ones, based on what we have, and of course hopefully, this can represent each university that already has its own system. Secondly, we will design, make and explain the framework that we have made, and hopefully, this can be implemented into the existing system, here need to be solid cooperation between the lecturer and the university, which we refer to as "One Voice". Third, we will provide an explanation of what we have created; we named it "Complaint Development Methodology". Why is this so important to do? There are several reasons that we need to understand:

a. The system does not present Complain "who" write and report

b. Complain current system has the properties of hit and run, where if a student reports a lecturer, the Department sometimes are subjective in to see it because there is no confirmation.

c. Complain existing system, does not contain the "Solution" and just focus on the problems and tend to marginalize both the lecturers and students. 
Here, we will try to put forward our point of view, with good intentions and did not intervene in any of the existing systems. If what we designed is useful, so use it wisely, if you already have a system that is already good, and then use it too wisely. We say: "Complaint is about how to change others becomes a better person, a complaint is not about how to attack others, and furthermore to become a wise complainer, we need to understand about the ethics and morality as well as spirituality (As Phycology side)".

In this paper, the discussion will focus on the innovation of the complaints process at the university, which is still the main problem. The innovation of the complaint process is already referring to the general standards contained within the university, but in the process sometimes there are still problems in the complaint. Therefore, the complain process requires changes in the process and is classified. The concept of competing with giants is a concept to know where the university is and how it can affect the university's progress in facing globalization. This concept is the development of the complaint system put forward by "International Student Complaint Behavior", Northumbria University, England and the Australian International College concept. These two systems will be developed into a complaint process at the university level, but certainly not out of existing and standardized cultures. This journal is an innovation of the standard of both concepts. The result of this journal is to produce a concept in complain systems so as to enhance the competitive advantage of universities in facing globalization.

\section{Method}

\subsection{Research Background}

The idea of this research begins with the observation of how the complaints handled by the academic community at the university in Indonesia. Data were collected through a survey on "How the complaints handled at university", with respondents consisted of 50 lectures and 50 students in several private in Indonesia. The study was continued by studying complaint management system that has been applied to two University outside Indonesia, namely, Northumbria University, England and Australian International College. The complaint system model that has been applied to both universities, the adjusted to the culture of education and management in Indonesia, so as to form a complaint system as proposed in this paper.

\subsection{Background Method}

If we observe and see complaints are rooted in our distaste for something, but what the real meaning of the complaint, the dictionary "Cambridge Dictionaries Online", complaint mean:

a). To say that something is wrong or not satisfactory

b). To tell someone formally that something is wrong. We can see clearly that the problems complain sometimes be subjective, giving rise to a misunderstanding between the two parties, so that when the root of a problem is not resolved then the result is misunderstanding lifetime, revenge, and hatred are never resolved. Moreover, for instance, there are some cases:

a. Students do not like the teaching faculty at the time, perhaps because of its teaching techniques; professors do not give good value to students; students do complain in any questionnaire or the form, and when the lecturer read it cause bad feelings and makes a campus environment becomes not conducive.

b. Problems between professors and lecturers, it is core issue, where lecturers feel they have the ability to be able to do everything without requiring the assistance of another professor, where there is no solid cooperation within the department resulted in the work being done by individuals never produce solutions or creativity

c. In a university system, may not apply to every university, every test there will be a test coordinator and supporters of the course, but due to lack of good communication between faculty, then the resulting excessive intervention and communications are so bad that misunderstandings occur among professors, lecturers that one feels has the ability and the right to be what jobs to do, but on one side of the lecturers that one feels has that ability as well, the result was again the environment is not conducive

With the complaint process to distinguish between undergraduate and graduate programs, the framework was created to address complaints systematically. In Indonesia, we need to look at this, that the complaints system at the University at this time still has a few things that need further development so as to produce a positive solution together and there where one party feels aggrieved. So we are here trying to make any solution based on kinship, in accordance with the culture in Indonesia. Based on The framework from the journal "International Student Complaint Behavior", Northumbria University, England. So we developed this framework to be tailored to the conditions in Indonesia and applicable to the University. 


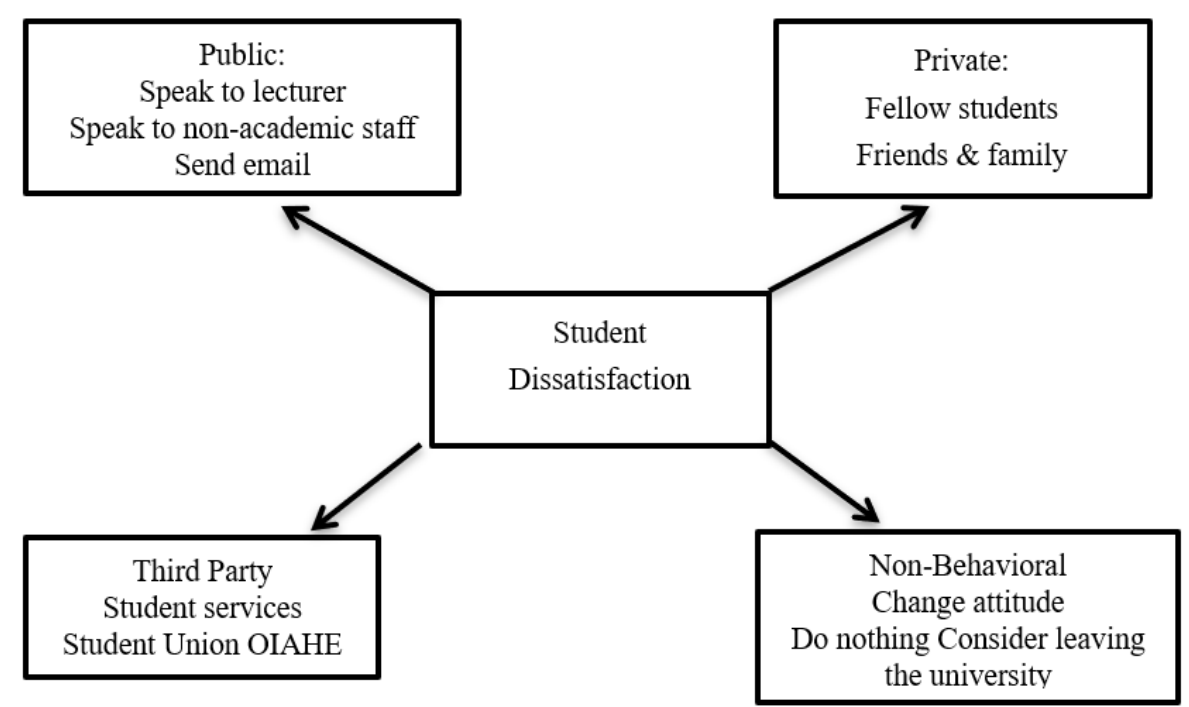

Figure 1. Typology Of Student Complaint Behavior(Hart \& Coates, 2011)

According to figure 1, there are four public processes; private; no behavioral; third party student service. In these four sections, each has a standard in the complaint service, if each process in these four sections does not meet the level of satisfaction, it will produce a degree of dissatisfaction. From these four sections, the process in the journal complain systems, developed from "private" and "no behavioral", these two parts are a proactive approach to students, so as to create a level of satisfaction. Next is the concept of complaint systems held by Australian International College, as seen in figure 2.

According to figure 2, The College has a complaints and appeals procedure to provide students with a fair and equitable process for resolving any complaints or appeals they may have. The complaints and appeals procedure includes a requirement that an independent mediator will be appointed if the student is dissatisfied with the process undertaken by the College. Complaints are to be recorded on a Complaint Form and are entered into corrective action database. A complaint may be about: (1) Trainer/lecturer; (2) Staff member; or (3) Another student unpleasant behaviour; (4) College's facilities; (5) Personal matters; (6) Assessment result or the conduct of assessment.

Assessing and responding to the internal complaint: (1) Once the complaint has been lodged, the complaint will be discussed in the weekly management meeting or in the office amongst the Principal, Course Coordinator, and/ or any relevant staff members; (2) Each appeal is heard by a person or panel independent of the complainant; (3) The Principal or Student Service Manager will give the student a written statement of the outcome and invite the student to arrange a meeting should they wish to discuss the complaint further; (4) In some circumstances a meeting will be arranged with AIC and the said complainant before a written outcome is issued to the student. This is based on the extent of the complaint/appeal. (The complainant may be accompanied by a support person at any time during meetings); (5) If the complaint is substantiated and favors the student the Principal and Student Service Manager will inform the parties involved via written correspondence and implement the necessary action/changes as soon as practicable; (6) If the complaint is unsubstantiated and favors the college the Principal or Student Service Manager will inform the parties involved via written correspondence. The student will be given a copy of the complaints and appeals process regarding external parties involved, the student has 20 working days in which to access this system; (7) All complaints will be scanned and saved in the student's folder and the Complaints and Appeals Folder; (8) All correspondence will be entered into the student database. 


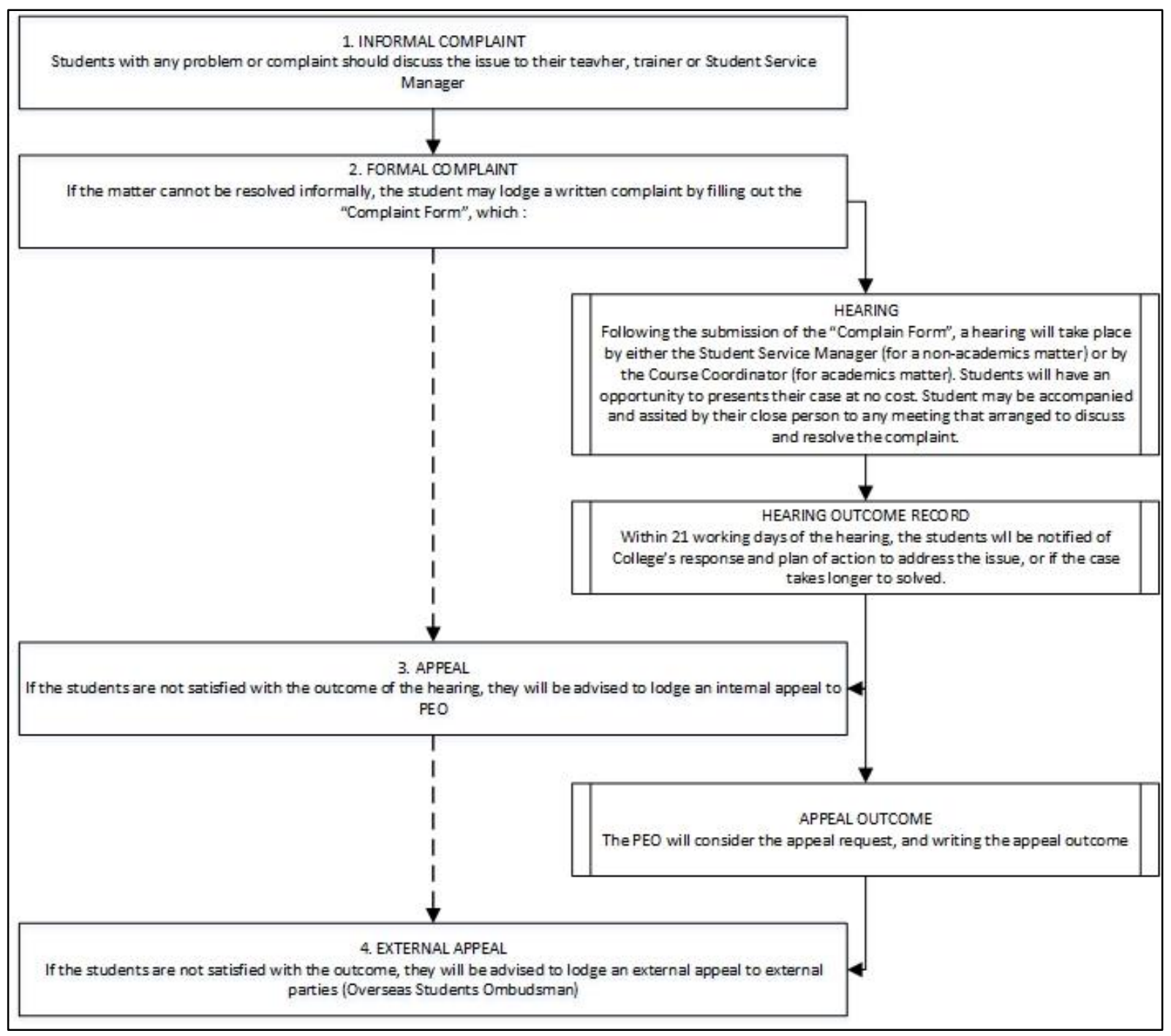

Figure 2. Complaint Process-Australian International College

The relationship between the two frameworks above with this paper are, first, private and no behavioral part, developed in the concept of complaint systems in producing good communication between lecturers and students; second, the concept of complaint owned by Australian International College, proactive processes- results and able to provide solutions to a complaint and what actions should be taken in solving the case of complaint.

It is both conventional and expedient to divide the Method section into labeled subsections. These usually include a section with descriptions of the participants or subjects and a section describing the procedures used in the study. The latter section often includes description of (a) any experimental manipulations or interventions used and how they were delivered-for example, any mechanical apparatus used to deliver them; (b) sampling procedures and sample size and precision; (c) measurement approaches (including the psychometric properties of the instruments used); and (d) the research design. If the design of the study is complex or the stimuli require detailed description, additional subsections or subheadings to divide the subsections may be warranted to help readers find specific information.

Include in these subsections the information essential to comprehend and replicate the study. Insufficient detail leaves the reader with questions; too much detail burdens the reader with irrelevant information. Consider using appendices and/or a supplemental website for more detailed information.

\subsection{Identify Participants}

In this paper, data collected with a survey of 100 participants, which includes 50 lecturers and 50 students in some private universities in Indonesia. With three important questions: (1) Is the service inside the university good 
enough so that you as a student are satisfied with the complain process ?; (2) Does the teaching and learning process include complaints if there are problems in the lecture ?; (3) Is the information and process in complain meets international standard ?. Where the points used range 1-5, where:

1: not satisfied

2: quite satisfied

3: do not want to answer / hesitate

4: good enough

5: good / very good

\section{Results}

\subsection{Survey Result}

Data from the survey has a results, 100 participants said: 20 people said "good enough" for the three questions; 11 people said "not satisfied"; 6 people said "quite satisfied"; 30 people say "hesitate"; 20 people say "good enough"; and 13 people say "good / very good". From this survey, we can conclude that the complaint process must be addressed at the most basic level, and this process should be able to provide a solution to the complaint.

\section{Participants's Answer Distribution}

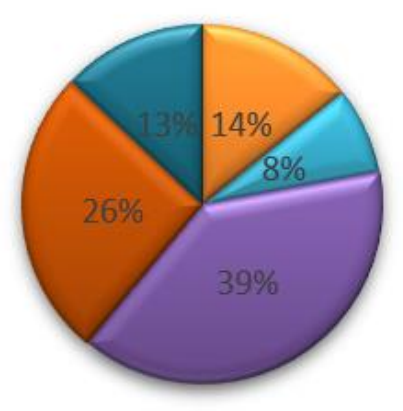

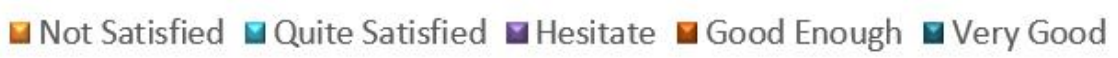

Figure 3. 100 Participants survey answer distribution

\section{Discussion}

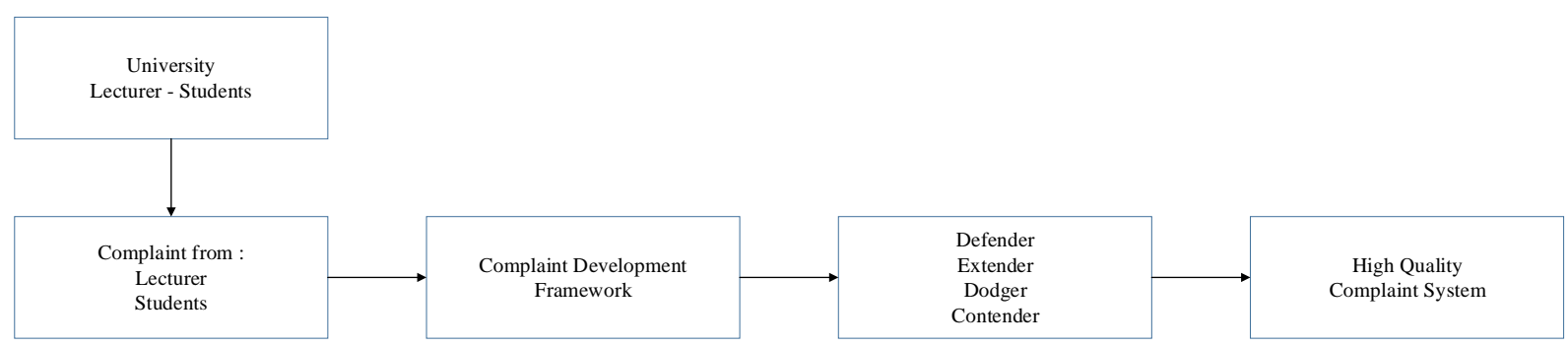

Figure 4. Process of complaining systems - the methodology of complain

In figure 4, we can see that the university has 2 important things in it, the lecturer and students. These two entities are the university's primary focus in effectively and efficiently processing in delivering high-quality education services. At the time of the complaint process occurs, this becomes an important issue that must be addressed immediately, because if we do not overcome it immediately, it will result in the quality of comfort at the university will be disrupted. Furthermore, this process requires a framework to make the complain process work correctly and perfectly. Next, in the concept of competing with giants from the Harvard business review, we will build a process that is linked to the four forces of the company in the face of globalization, whether this can be linked with the university? the answer is yes, it can be linked. Four things will provide a final solution in improving CRM at 
the university level so stakeholders and shareholders within the university will be able to obtain satisfaction and comfort levels in addressing complaint issues.

\subsection{Proposed Complaint System}

\subsubsection{Framework L To S / S to L (Lecturer to Student / Student to Lecturer)}

Here there is a draft among the lecturers to the students [L to $\mathrm{S}$ or Lecturer to Students] and Students to Lecturers [S to L or Students to Lecturer]. Why is necessary to first separation?, there are some classic case here, that sometimes the student when giving his opinion or filling questioners subjectively, for example: if the professor present on time, teach well, giving a value corresponding to the capabilities of the students, then if the value of the end result is not good, then most students give an opinion are not good for the lecturers.

On the contrary, the lecturer cannot provide any rebuttal against the student. Moreover, if a student is good, critical and has the incredible ability, and when asked, the lecturer was defeated in this case, it can only be a lecturer is not like it and the final result of the student is not good. The things above are the classic case, which may be until the world ends there will never be the solution, because both sides feel is unfair, and the one to blame each other. There was never a meaningful and significant settlement.

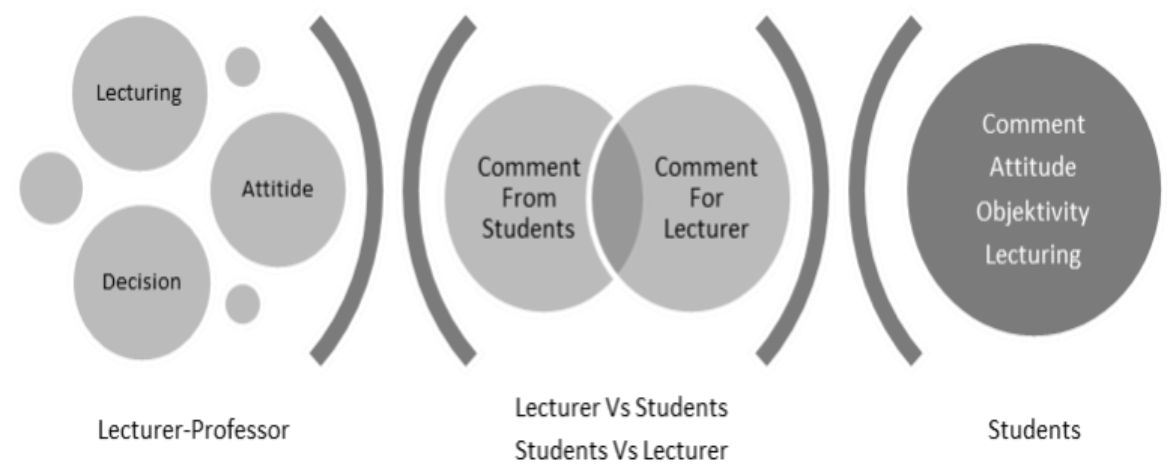

Figure 5. Framework L To S / S To L

According to figure 5, in this framework, we can see the things that cause friction is that lecturers find that a student did not give his opinion correctly, and students feel that professors do not fulfill their wishes. The first thing we must understand is that the university is "Education" instead of "Means of battle" or "Means Negotiating Values". Education focuses how the student will get more value from what is taught by an educator, and educators should be able to do that, not only did his duty as a lecturer, but more than anything it has, the intention is not just focused on the textbook without giving the values of life that can change the lives of students. We say, "The best lecturing come when we have a heart to our students, we care about their future, not ourselves". We will explain in more detail in the framework.

\subsubsection{Framework L to L / S to S (Lecturer to Lecturer / Student to Student)}

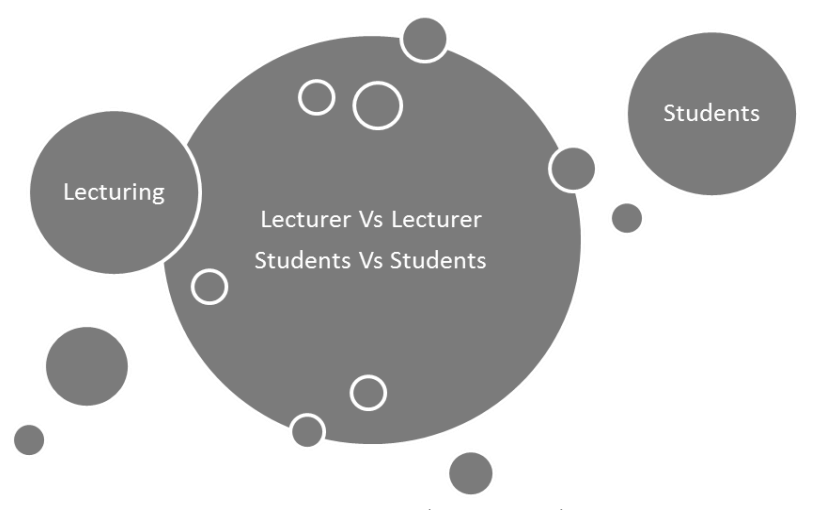

Figure 6. Framework L To L / S To S

According to figure 6, in this section, we will discuss how lecturers do complain to another lecturer and students can complain to other students. It should be noted here, that this section is not intended to play off between lecturers 
and lecturers, students with students, although there is the word "Versus". Here we learn to understand that provide critical feedback or to fellow was very well done, but that should be used is a constructive one another and not criticize each other with the intention of dropping one another. It should be acknowledged this is not an easy thing, because here the necessary attitude open to each other, the attitude to want to cooperate and more positive attitudes such as humility, teachable attitude, learning, empathy and so on. “...studies of leadership have typically drawn on a narrow range of functionalist theories..., using positivist methodologies, and producing quantitative findings through large scale surveys. As a result, empirical findings have tended to be rather objectivist, essentialist and functionalist, frequently abstracted from specific local contexts. According to Garcia, "the nature of the research undertaken by business schools tends to focus on academic matters 'utterly divorced from the challenge of everyday management'(Garcia, 2009)

For example: when a teacher found the other lecturers academic offense or commits an act outside the limits of the student, it helps if fellow professors were reprimanded for goodness together. Is this hard to do? For us not, because if the foundation is objectives to see the problem in a positive way and have a viewpoint that is open, then everything becomes easier to do, but if the foundation is built are competitive and want to feel yourself to win, then it is difficult to apply Complain Systems.

On the one hand, we should be able to see the students also need a means to complain against his friend. Why? It is useful to keep the situation is conducive. For example, when professors assign tasks to students in groups and there were students who did not do his work together, then other students can complain against his friend through the means that have been provided by the college.

\subsection{A New paradigm: Complaint Development Methodology - The Framework}

We designed three pieces for the framework, but the framework is essentially a unity, not separate from one another:

a. Figure 7 is a drawing framework of "Complain Development Methodology", this is the first layer framework, which is used as a common standard so that everyone can use it. But although the first layer, it should already be used to solve a complaint within the University/department

b. Figure 8 is a framework for special cases and severe cases, where the student/teacher suffered severe cases, such as sexual harassment, other abuse, physical violence, extortion, and a lot of negative things and evil experienced by faculty/student , Framework is the second layer, which is a special framework overcome specific problems and other serious violations.

c. Figure 9 is a framework to address the issue in greater detail, it is intended that the problem can be quickly resolved, without wasting a lot of time and a waste of energy, focusing on the immediate problem to be solved, so it can be said "face to face", "head to head" and how everything becomes transparent. This is the third layer

The third framework is presented as follows, especially for how we use this framework and how to apply it to the University, then after three such images will be given an explanation.

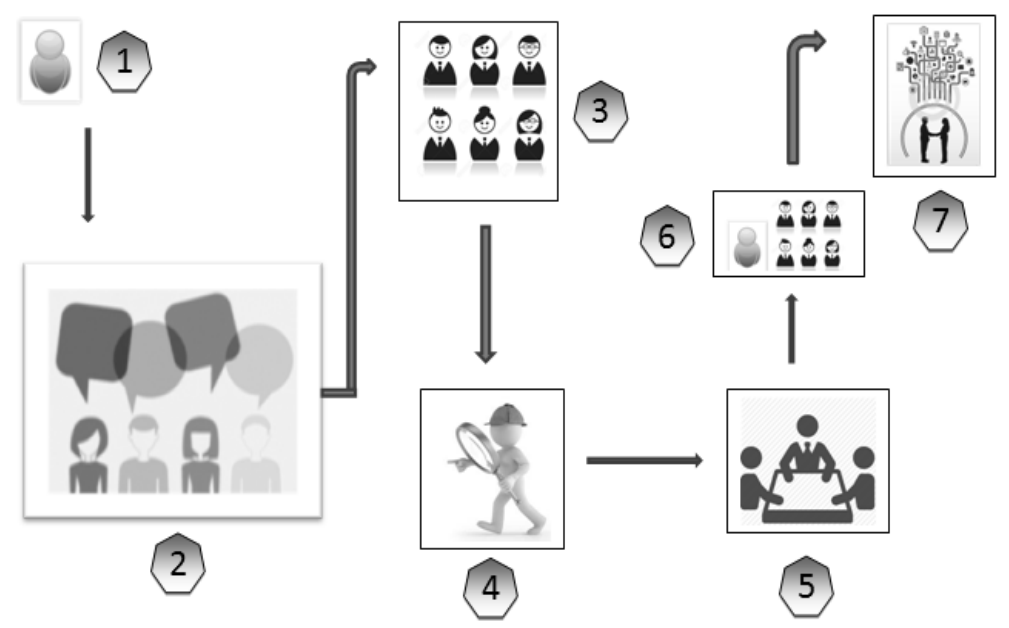

Figure 7. Framework The Formula "L [Lecturer] To S [Student] /S [Students] To L [Lecturer] + L [Lecturer] To L [Lecturer]/S [Students] To S [Students]"- Complain Development Methodology 


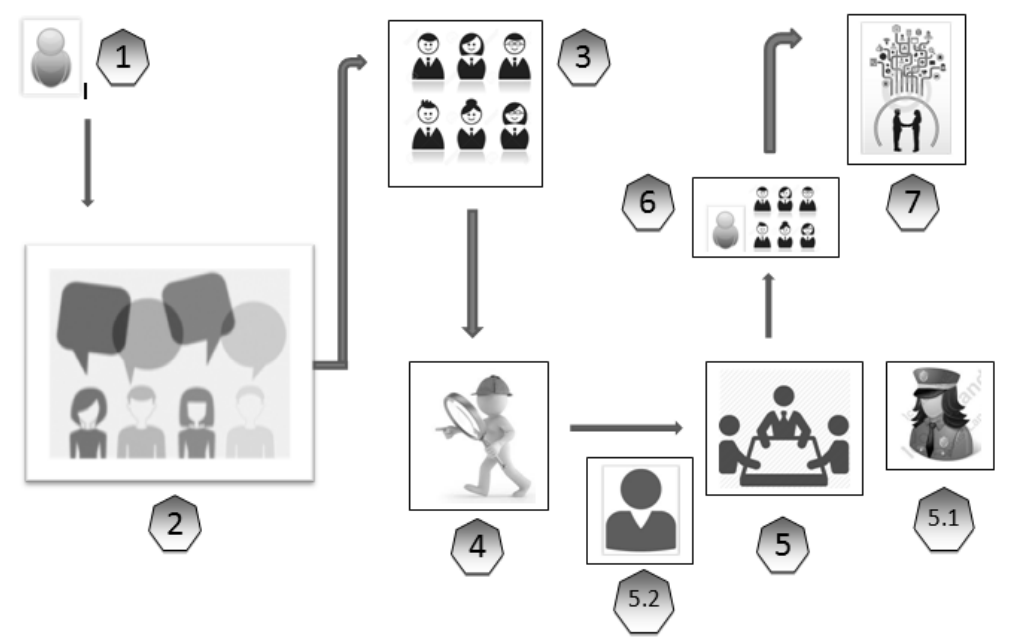

Figure 8. Framework The Formula "L [Lecturer] To S [Students] /S [Students] To L [Lecturer] + L [Lecturer]

To L [Lecturer]/S [Students] To S [Students]"- Complain Development Methodology- Difficult Case

Explanation of parts of the Framework "Complain Development Methodology"

(1) Students

(2) Application Complain - Integrated Systems \& Transparent

(3) The Focus Group \& Solve

(4) Investigation

(5) Meeting

(6) Students \& (The Focus Group \& Solve)

(7) Win-Win Solution

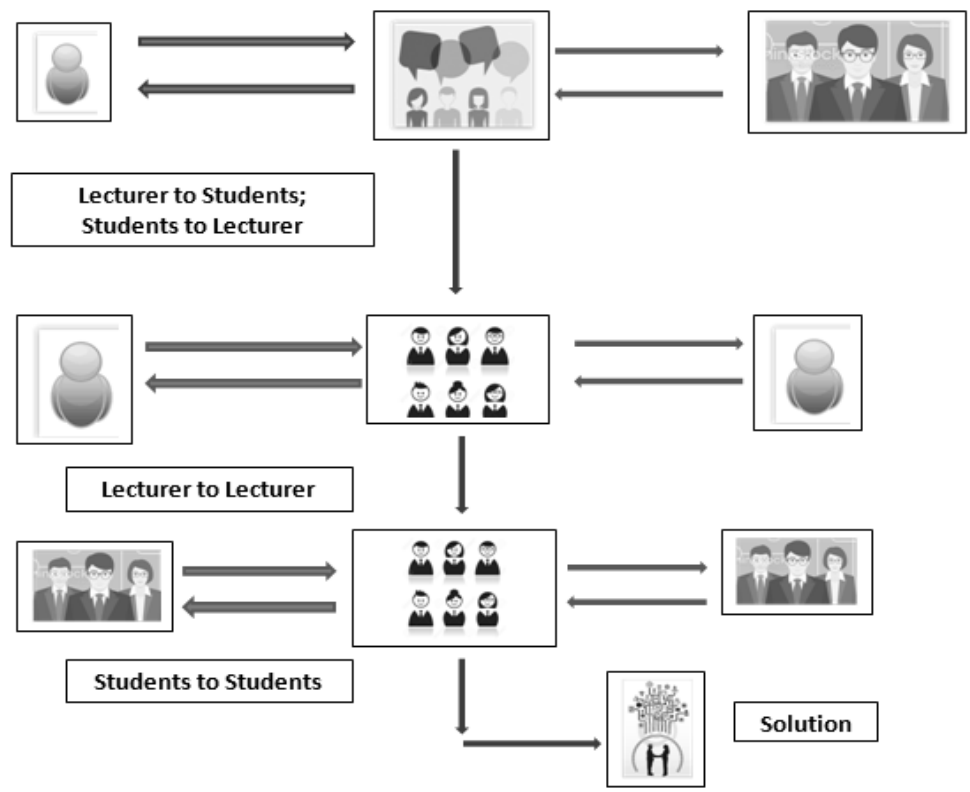

Figure 9. The Process of Complain 3 Layer

(Layer 1: Lecturer To Students-Students To Lecturer, Layer 2: Lecturer To Lecturer, Layer 3: Students To Students)

In layer 1, we see that when a student has a problem, first of all, he had to do reporting publicly in a designated place, such as a place that is shaped like social media (which was created by the University) and/or an application, and / or forum, where there must be transparency, where the full name, student registration number, Smartphone, 
E-mail, Department, Class, with group classes and courses, and must be accompanied by authentic evidence that exists. At this stage, the reporting should be open and very transparent, which the teacher can respond to what complained by the student, the student must be able to present strong evidence and/or witnesses were already there (witness is required to also list the same as students who do complain ), this is done to avoid misunderstandings between lecturers and students. But, the question is whether this ethical? we answer: ethical, during this general case, as the lecturer did not attend the lecture on time; professors never teach correctly, the lecturer did not leave tasks that should have been; lecturer with poor behavior to follow and there are many other cases, but again keep in mind, that this is a special case. Students do complain, the lecturer responded. Next question: Who can see? Only the class, not the entire department, and one more important thing, that all complaints should be stored in a database with a very neat, and the chronology of the problems must be told in very details by students, not only, for example: "Lecturers never sign on time ", when the complaint was made, concrete evidence of what can be shown and posted by students, and at the time the complaint was made a lecturer responded by chronology as well. All complaints cannot copy and paste, and is transparent but special. Students who violate copy and paste and post on blogs can be sanctioned by the University as defamation. Is this too hard to do? Again we answer, No!. Why? Because here we learn good manners, transparent and look for solutions together, not one party feels right and the other party constantly blamed by the act that was never done. And strictly forbidden contains elements of racial intolerance, excessive abusive elements and so on, in accordance with that contained in the Act ITE and Hate Speech from the police, to avoid subjectivity. If the problem can be solved at this stage, it can be said to be completed, with two people who give a proof of a written statement signed by both parties, so that cannot be leveraged back. However, if the problem cannot be resolved, it can be brought to The Focus Group \& Solve, consisting of Head of Department / Head of Studies Program; Chairman of the Association of Students majoring / department; Chairman of the Executive Board of the student; 2 Lecturer (here is not specified whether it should be a senior lecturer or not, we've seen is whether the lecturer has integrity), Dean / Vice Dean. Furthermore, an investigation into the professors who complained by the student, and must be confronted by faculty and students, so here no game "Throwing stones hidden hands". The next stage, after an investigation it conducted meetings between students who do complain, complain and lecturer at the Focus Group to solve these problems. the end result should be reconciled, because the evidence already exists and if the professor who does have a problem, then Focus groups can impose sanctions first, then sanctions the second and third, but the fourth sanctions are dismissal by the University, on the contrary, if the student the slander and the evidence cannot be presented, even lecturers to present the evidence against the student, the university will do the same thing with the sanctions first, second, third and ended with the issuance of these students. According to Crosson: (1) Safety. All children have the right to live in an environment free from abuse and neglect. The safety of children is the paramount concern that must guide child protection efforts; (2) Permanency. Children need a family and a permanent place to call home. A sense of continuity and connectedness is central to a child's healthy development; (3) Child and family well-being. Children deserve nurturing families and environments in which their physical, emotional, educational, and social needs are met. Child protection practices must take into account each child's needs and should promote the healthy development of family relationships. (Crosson-Tower, 2003). The most important point is, the students in university are like children that need to be hear and understanding.

The most important thing at layer 1 is that we learn to not arbitrary to say something without evidence, and hear only as a thing that is not clear and details; investigations must be carried out with the details, not just received a report on the one hand and made a reference to decide something.

The biggest mistake that puts a strain on a system is that we only hear one side of our ears. Layer 2: "Complain Development Methodology" - Difficult / Hard Case: (5.1) Police (5.2) Rector for this layer 2 is a way to complain of severe cases, such as sexual abuse, physical abuse, physical violence, harassment in the classroom and in cases deemed damaging to morals and ethics. The difference with the first layer is the layer 2 and the rector presented by the police and/or the chairman of the foundation of the University. But this phase will be done as well if the evidence and the witness strengthen the complaint in details and objectivity. First, it is better if there is the rector and/or chairman of the foundation, in a sense, the problem resolved internally without involving external parties, if it is done already exceeded the limits of moral and ethical, it can be presented by the police, even forged the signatures of professors by students also it should be taken, in order here to create people who are not rigidly follow the rules, but it should be so that should be done. There are rules and regulations that have been written and must be run properly. Layer3:"Complaint Development Methodology" - Specific Case. The third layer is the most difficult complaints system, where each party is required to have evidence, witnesses and break-objectives- openly and without bringing other elements apart from the problems to be solved. The nature of subjectivity is a trait that can be done when a person acknowledges his guilt and given the opportunity to change but within the limits that have been determined by a final decision made by the first and second. Group Focus has been described in layer 
1 and 2 and here will explain what is meant complain lecturer at the faculty; student to student. Is it very urgent to do?, we say: Yes !. Why? Due to maintain the conducive environment, the convenience of teaching and communication is very professional. First, namely complain between lecturers to professors: Specific to this case, as an example, there is one subject that is taught by a course coordinator which might lead to 2-4 lecturers (depending on the number of classes and students taking the course). at some point, some of the students reported that lecturers and never went and always late and/or case of the worst is the lecturer just told students absent and after that professor were never taught for several weeks, then the student can report directly to the coordinator of the course, then coordinator confirmed the lecturers B, if the professor B denies that never do that, then the coordinator can bring the case to the Focus groups with students who reported to be solved, once again the coordinator must have evidence and witnesses were strong at the time of reporting, of course, it is from the beginning students reporting that provide authentic evidence, if there is no evidence, then the case will not be processed. As another example, if a lecturer harassment or immoral action to the student, then the first thing that must be done by the students is reported in one of the professors who believe, then lecturers confirmed to the lecturer concerned, whether true or not? If you deny and say not, the student must provide evidence that much anymore in order to solve problems. Mind and note here is that professors report other lecturers do not violate ethical and moral, but with a very important note that the evidence and witnesses to be true -Right presented not only the words and reporting without proof, to maintain order, reported to be confirmed lecturer, presented together with the report, it is to actually maintain mutual slander and stab each other in the back, because some cases specific, resulting attack against other lecturers.

Lecturers who have integrity should not be worrying that we say: "Lecturer must give an example of his / her attitude, words and what they're doing, so that, the students will change too. Moreover, Also students must change their attitude, words and what Reviews their doing, Become an honest students ". Develop a project outline or statement of work the problem description. This must contain the anticipated benefits or outcomes of the project and the scope or capabilities of the proposed solution (Thompson \& Toohey, 2014)
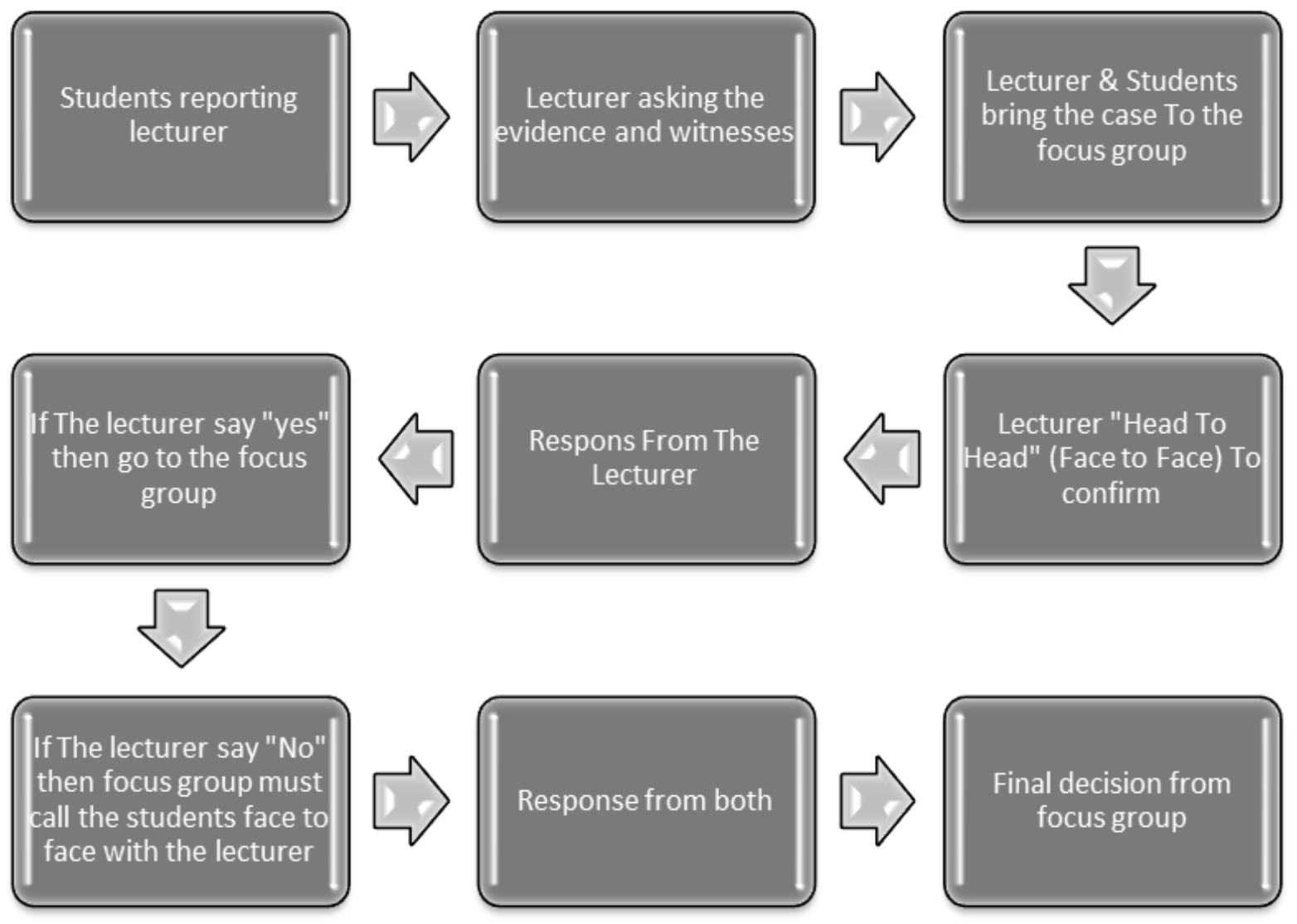

Figure 10. The Process of Reporting \& Communication Students to Lecturer [S To L]

The Beginning From - "Students Reporting Lecturer" 
The second thing is the Student to Student. In this section, students must be active for adults provide a report to the department/department, or a faculty member teaching the course, in severe cases; it will be brought to a focus group. For example: In one course, e-business, at the time of assignment, one group consisted of 8 people, so if there is one student who did not to do it, then the chairman of the group, first, to report to the faculty member teaching the course the then faculty calling students at a specified time, if still not present it will take firm action, if it is present, then the lecturer to discuss in advance with students who reported it, and furthermore, professors summoned the head group and his team together with students who reported to be confirmed directly, whether true or not. Another example is with a centralized system, application / program / social media or whatever its form, students can give its opinion on it, as long as it must always be accompanied by evidence and witness authentic, here we would like to provide input, that any reporting must always accompany by evidence and witnesses, if reporting is only based on "reports" without evidence and witnesses, and a lecturer took the action based solely on the report without evidence and witnesses, the lecturer was penalized, which means it is a slander (hoax ) which was executed without considering the side effects in a situation, resulting attack against other lecturers. Even these ethical and moral rules apply to students; here order must be maintained so that there is mutual discredit each other. According to Uppal, Customer complaint arises due to:1. The attitudinal aspects that deals with customers; 2. Inadequacy of the functions/arrangement made available to customers or gap standards of services expected and actual services rendered. (Uppal, 2010).

In this section, the point that needs to be understood is that the focus group must have an objectivity level in determining whether this error can be tolerated or not, therefore the focus group must have integrity in making decisions, they should be able to see the big picture of a problem that is then drawn to a just and true conclusion, so that the decisions made will be very objective. The nature of this objectivity must be owned by every member of the focus group, and special titles, no limit is specified, that is, it does not have to be a Ph.D. member who must be a focus group, but a Master degree can be allowed. This Focus group should have at least 5 years' experience working as a lecturer, as this may provide maximum service for complaint. Service to overcome complain must have people who have high experience in counseling, so the relationship between lecturer and student will be able to be well established, furthermore, will get maximum result to give solution to student in overcoming various problem. Some dissatisfied customers may not voice their complaint to the product/service provider, but may use other avenues to complain such as negative word-of-mouth, aggression, taking the business to a competitor elsewhere, among others (Nimako \& Mensah, 2014)

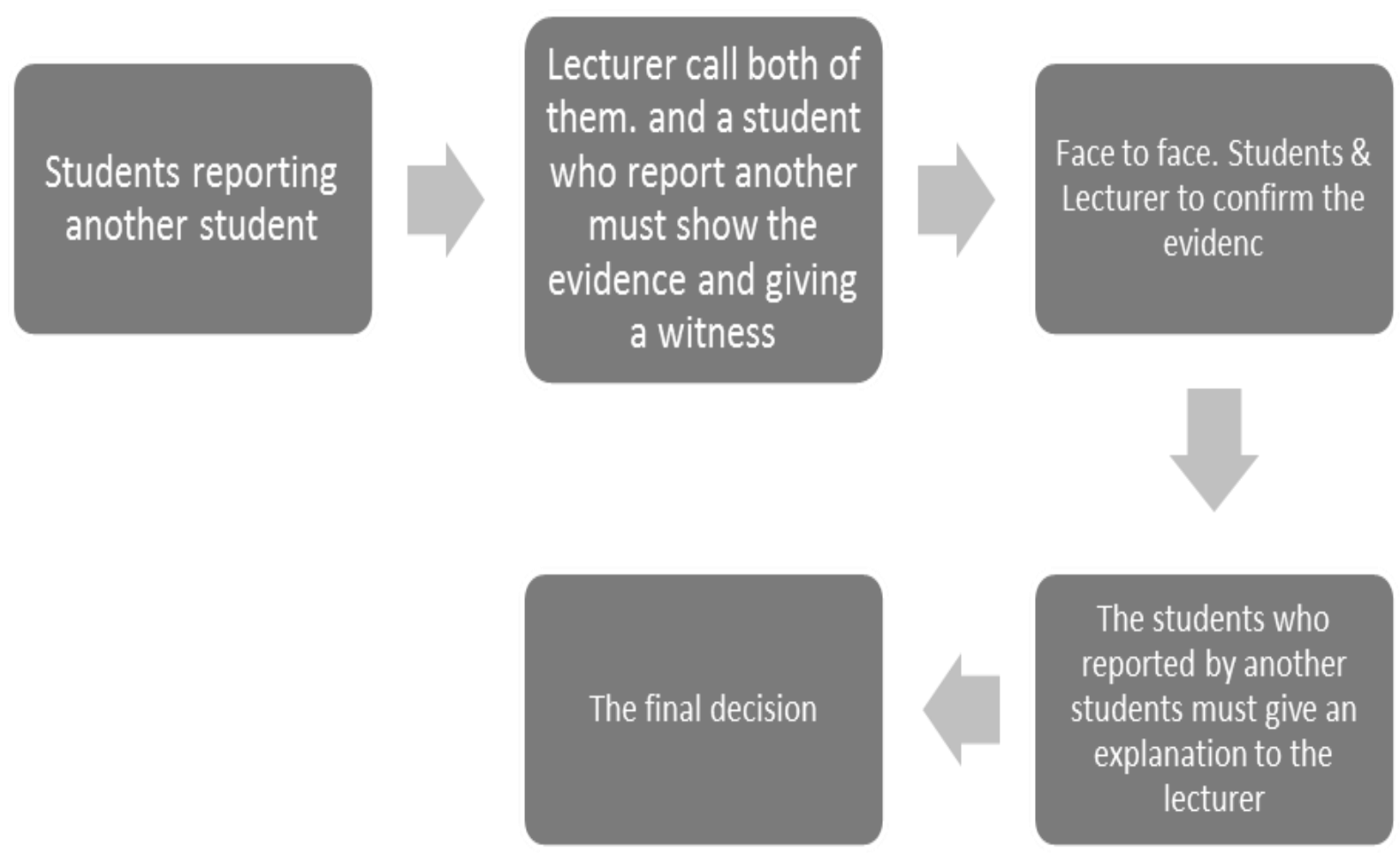

Figure 11. The Process of Reporting \& Communication Students to Students [S To S]. The Beginning from: "Students reporting other students" 
According to figure 11, we can see that the process of reporting from students to students, this should get the right solution, because this will be able to maintain the level of comfort in the campus as well as learning. In this section it is very important to do carefully, evidence and witnesses must be objectively presented, as this will solve every case by using the principle of justice for all. In critical reporting, such as reporting by students' abuse to other students, this should be dealt with promptly, correctly, and requires a firm solution, because, in the absence of an uncertain solution, this can lead to disappointment, then will cause damage to the name of the university. In severe cases such as engaging in drugs, committing both small and medium-sized crimes, it must be submitted to the police, for a more equitable legal settlement in the future, and for example for other students not to do so the same one. Next, for example, in the case of using highly dangerous weapons, this should also be left to the police to be handled immediately and in need of legal settlement. This reporting should first be addressed by a focus group university, which will then determine the severity of a case and the appropriate solution to address it, many of us allow a case of complaint so that it develops into a case that never gets the real solution. Students as reporters should be able to present witnesses and evidence, in order to provide justice and respect for human rights from being reported. This reporting should be noted and well documented by the university, so the university has an accurate database with every problem, so if a similar case arises at the university will be able to see the history, whether the problem has ever happened, and soon be given a solution to overcome, but here, of course, the need for creativity to overcome every case of complaint, we must not equate between the case that has happened and the case that happened now. At the midpoint of the old and new cases, there is a missing link that must be drawn to a creative solution and based on appreciating each right that is owned by every human being. Many of us allow this and sometimes assume that it is unimportant, causing an ever-increasing problem or problem that never resolved until the students graduate from the university. This should not be the case, as far as a case of complaint has a greater degree of incidence, we should be able to learn to address the complaint case with the result of reducing the level of impact, rather than accumulating future impacts. All of this will be able to deal directly with the level of integrity of the university. The most ironic thing is that if a case is left for a few months, and as if missing from the real problem, the impact of this is the damage to student psychology and the degree of university comfort, what is the most severe impact of all of this? , the university will get a bad name in the community and the level of public confidence in the university will drop drastically. How, and to what extent, can the delivery method predict student delivery method satisfaction after controlling for the students' delivery method experience level? (Yen, 2014). The worst thing that happened was that the university would be closed because no community believed to send their children to the university. What results will the university achieve when it succeeds in minimizing the possible complain problems in the learning and overall university?, students will be able to learn with a high level of comfort, the community especially the parents will believe that their children get the best out of the university such as- education (science); good character; properties that are very useful for the future, and many other things to be had. Therefore, caring is the only starting point for creating a high quality complains system. Furthermore, the level of complaint between students and students will be overcome very well, where each side will learn to realize the mistakes it has made, and increase the level of maturity.

\subsection{Defender-Extender-Dodger-Extender}

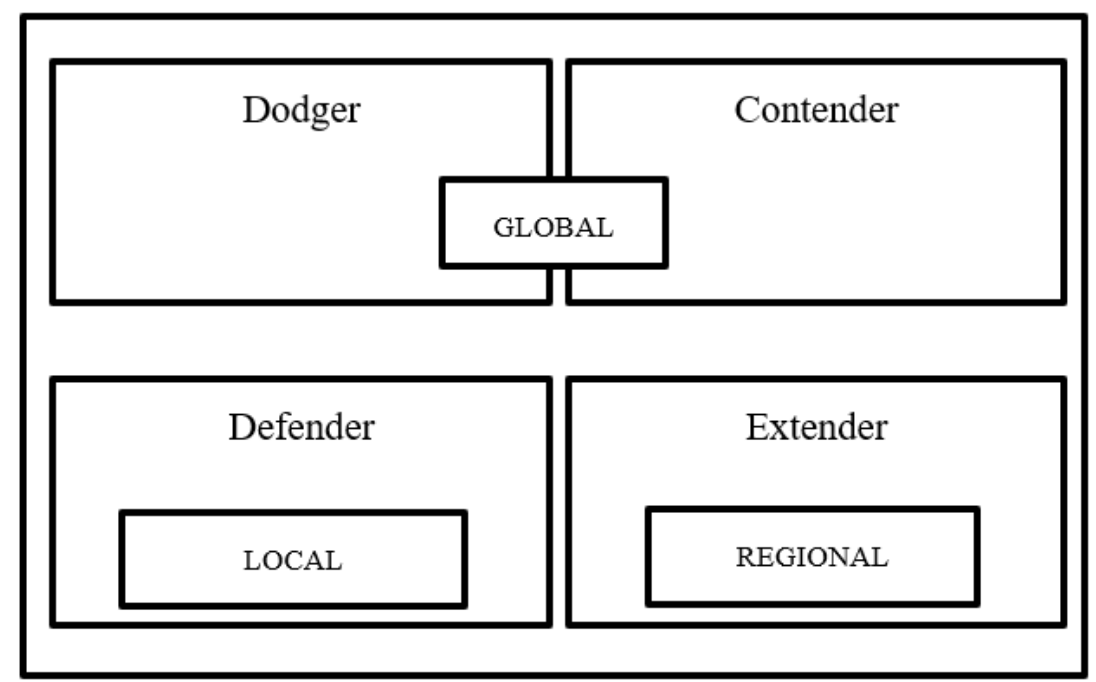

Figure 12. Competing With The Giants(Czinkota \& Ronkainen, 2007) 
Conceptually, the defender has the meaning of focusing on enlarging the local competitive asset on the market segment, where the multinational corporation is not so strong. The key to success for defenders is to concentrate on the advantages they enjoy in their home markets. They often need to tailor their products and services to specific customer needs and are not uncommonly unique. Defenders need to resist the temptation to try to reach all customers or imitate multinationals. The defender will perform better by focusing on consumers who value local touch and ignore consumers who prefer global brands. Being an extender means focusing on developing markets to neighboring countries by relying on domestically built competencies. By having the right assets that can be moved, the extender companies can use their successes domestically as a platform for expansion to all places. Extender companies can enlarge their assets more similarly by searching for similar markets, similar markets that are similar to markets in their home country in terms of consumer preferences, geographical proximity, distribution channels, or government regulation. If a company with only strong domestic competitive assets is facing strong pressure toward globalization, it must be a dodger. The company will not be able to rely solely on its local assets but must rethink its business model. If its assets are only valuable in the country, then the best way is to do a joint venture or sell their entire company. Being a dodger is probably the hardest choice to implement from all four of the above, carefully selected; a dodger company can use its local assets to build an active position. Last is to be a contender. Being a contender means doing all the effort to develop its competence in the global marketplace, and therefore competing head-to-head with other global companies. Here the company must still consider its sales strategy on a global level. If a competitive asset is movable, it may be able to transform itself into a full multinational. A contender company focuses on enhancing the capabilities and resources to compete with multinational companies globally, often by persisting in its market niche.

Understanding these four things, if we connect it with the university especially CRM system complains systems: In Figure 12, we can see that there are four important parts: defender; extender; dodger and contender. In the defender section, the university reinforces the existing system, where a well-established service system is maintained and any system that has been running effectively and efficiently is maintained. Next, the University developed into an extender, which means that universities that already have an existing complaint system develop the system, in collaboration with outsiders who have the competence to develop a system of complaints that have been very well applied. For example, company A has managed to increase consumer satisfaction by creating a complaint system that can make customers comfortable and satisfied with the company. Applications that they have can provide solutions to consumers and keep the company from the problem. The University, in this case, can collaborate to create an application that can be implemented in the system, so that CRM at the university level can run effectively and efficiently. In this paper, a framework was created to address complaints at the university level, so the university was able to achieve a fairly stable CRM level (Pratikna \& Gamayanto, 2017). On the other side, the university in addition to improving its complaining system, the university must change its business model to be compatible with the development of information technology. If the university does not want to change its old business model and still maintain an old business model or system that cannot keep up with the development of information technology, this will result in the university will be shifted from the existing competition. At the last stage, the university may turn into a contender, which means that once all the assets owned by the university can be transformed into an asset that has the potential to be developed around the world, the university must be able to sell the asset boldly to apply it in other universities, it is intended to be able to deploy a system that has proven reliability (Gamayanto \& Esti Nilawati, 2017). The final results to be obtained by the application of this complain system are: (1). The relationship between lecturers and students will be better and more stable; (2). Solutions will be more precise to the goals as they are governed by the focus group, which is the group to be the middle party and consists of people with experience; (3). Solutions are not only based on technical matters, but there are other aspects to note such as the psychological side and the issues in the past that must be explored more deeply before providing solutions; (4). The familial system will be more applicable when the complaint system is used; (5) The legal and justice system will be executed properly and appropriately; (6). The level of comfort in the university environment will be more stable and well maintained; (7). Relationships can be further improved especially in the learning system in the lecture. Things like this will be obtained when applying the complaint system effectively and efficiently as well as the intense collaboration between the parties in the university.

\section{Conclusions}

- The system complaints can be made if accompanied by authentic evidence and witnesses, in cases complain now, just based on reporting without evidence and witnesses, so this is an inconvenience in a campus environment; it needs to be examined with a critical priority because this is a matter that can cause problems.

- For A Special Complain Systems such as Lecturer complain to the lecturers, students to students, should 
be accompanied by evidence and witnesses were very authentic, where the system is made not to attack each other, but learning in order to maintain order, ethics, and morals

- Complain Systems layer 1 and 2 can be done with the record, the University provides a facility, whether it's an application/program / social media/forums. Specially made, and here every complaint must be transparency, there is no anonymous reporting, Student Identity and so on, to keep the reporting whether authentic or not

- Peter F. Drucker, in The New Realities, said, "Management is concerned the man. Duties to make people able to work together, to make their superiority helpful, and their weaknesses irrelevant. This is the purpose of the organization, and this is the reason why management is a determining factor ". This statement is a very important thing to be noted by every university in Indonesia, Top Management in the University should be able to include things that have been put forward by Drucker, because sometimes the management system is not neat and standard operating procedure (SOP) that are not obviously going may result in complaints and discomfort within the University. We can illustrate this in a simple, a building needs a foundation strong foundation, if the basic foundations are not strong then the house will be able to collapse, or in other words a building homes that are already built but after so the poles are tilted, it will be difficult to fix it, and at the time wanted to fix it needed overhauling bottom. This is a simple illustration that reflects the basic strength needed to build a solid university management and/or Standard Operating Procedures (SOP)

\section{Recommendations}

a. Before students enter the room faculty, the student is required to make an appointment in advance by the administration to see the schedule of consultations held by the lecturer. It is very necessary to be able to make the rules clear because there are some cases no communication between faculty and students will lead to complaints of students to lecturers.

b. Each student consultation with faculty, in some cases, teachers can record the discussion by CCTV to avoid libel and untrue reporting. For this process still need to be discussed further as a matter of privacy, some people do not like to be recorded at the time of the conversation. It is better if it is made a specific or special rule for special cases, as is to keep both parties feel comfortable and to avoid misunderstandings and complain to each other, where one party feels uncomfortable.

c. CCTV (Closed Circuit Television) installed lecture room to make it look the learning process is transparent, so that any complaint/report is only based on what is right, not only are subjective. For this case, the recording during the learning process, is one thing that needs to be made a special rule also, we must first understand the usefulness of the recording when the lecture takes place, whether it is used as a means to simply share the knowledge to the public or to process distance learning (where there are video lecturer, specialty students who do not attend lectures). Universities can create a special rule to be able to implement this; several universities in Indonesia have applied this and create rules based on ethics education so that faculty and students can work better.

d. Concepts from Daniel Goleman, Emotional Intelligence to faculty and students. Which includes 5(five) important factors are divided into two parts:

(1) Personal Skills, which include: self-awareness (understanding of the status of self, preferences, resources, and intuition); Self-regulation (Managing condition, impulse, and the resources themselves); Motivation (emotional tendency who will take or facilitate achieving its objectives).

(2) Social Skills, which include: Empathy (awareness of the feelings, needs, and interests of others); Social skills (versatility in touching the desired response in others).

This concept can be applied to the current complaint system of the University; we believe it will find a solution to overcome the problem. We can call it "Emotional Intelligence Communication"

e. Three Questions Before implementation of the complaint system, the system will be able to assist in the process of resolving the problem in the complaint, among other things:

Q1: Do I have a policy of open ears?

Q2: Do I interrupt / Like interrupted during the conversation?

Q3: Do I want to hear something that I need to listen to?

$3 \mathrm{Q}$, if implemented well, then we believe that the issue can be resolved by either complain, because there is no problem so big, so there is no solution in it. Most of us have the ability to speak but has the ability to hear very 
less, it is worth noting that $3 \mathrm{Q}$ is when applied, lecturer in advance to apply it to himself/herself, so that students see the level of maturity in communicating, we believe that by practicing the $3 \mathrm{Q}$, then will form a conducive environment so that the relationship between faculty and students can be very well established

f. Research, it can be continued by applying to one department first, but it should be understood that new standard operating procedures should be created to run this complaint system

\section{Acknowledgments}

Mr.Henry Christian, as a business owner, providing information and assisting in collecting the required data, a businessman with the necessary research and expertise in applicable practical logic and information on what industry / company / organization needs.

\section{References}

Australian International College (2018). Complaints and Appeals procedure, Australian International College Pty Ltd trading as Australian International College. Retrieved from http://aic.nsw.edu.au/complaints-appealsprocedure/

Crosson-Tower, C. (2003). The role of educators in preventing and responding to child abuse and neglect. Retrieved from http://childwelfare.gov/pubs/usermanuals/educator/educator.pdf

Czinkota, M., \& Ronkainen, I. (2007). International Marketing.

Gamayanto, I., \& Esti Nilawati, F. (2017). Pengembangan dan Implementasi dari Wise Netizen (E- Comment) di Indonesia. Techno.COM, 16(1), 80-95.

Garcia, E. J. (2009). Raising leadership criticality in MBAs. Higher Education, 58(1), 113-130. https://doi.org/10.1007/s10734-008-9185-6

Hart, D., \& Coates, N. (2011). International student complaint behaviour: Understanding how East-Asian business and management students respond to dissatisfaction during their university experience. The International Journal of Management Education, 9(4), 57-66. https://doi.org/10.3794/ijme.94.380

Nimako, S. G., \& Mensah, A. F. (2014). Exploring Customer Dissatisfaction/Satisfaction and Complaining Responses among Bank Customers in Ghana. International Journal of Marketing Studies, 6(2), 58-72. https://doi.org/10.5539/ijms.v6n2p58

Pratikna, R. N., \& Gamayanto, I. (2017). Developing Leadership Systems Inside University Using Jim Collins Method [ Good to Great ]: People Management Development to Face ASEAN Economic Community in Indonesia. Review of Integrative Business and Economics Research, 6(3), 45-55.

Thompson, N., \& Toohey, D. (2014). Teaching Case Analysis of an Electronic Voting System. Journal of Information Systems Education, 25(1), 13-22.

Uppal, R. (2010). Customer complaints in banks: Nature, extent and strategies to mitigation. Journal of Economics and International Finance, 2(October), 212-220. Retrieved from http://www.academicjournals.org/JEIF/PDF/pdf2010/Oct/Uppal.pdf

Yen, W. H. ; C.-J. (2014). The role of delivery methods on the perceived learning performance and satisfaction of IT students in software programming courses. Journal of Information Systems Education, 25(1), 23-33. Retrieved from http://ezproxy.lib.ucalgary.ca/login?url=http://search.ebscohost.com/login.aspx?direct $=$ true $\& \mathrm{db}=11 \mathrm{~s} \& \mathrm{AN}=99018391 \&$ site $=$ ehost-live 


\section{Appendix A}

\section{The example of Student Complaint Form}

This is an example of Student Complaint Form taken from Australia International College, 2018.

\section{STUDENT COMPLAINT FORM}

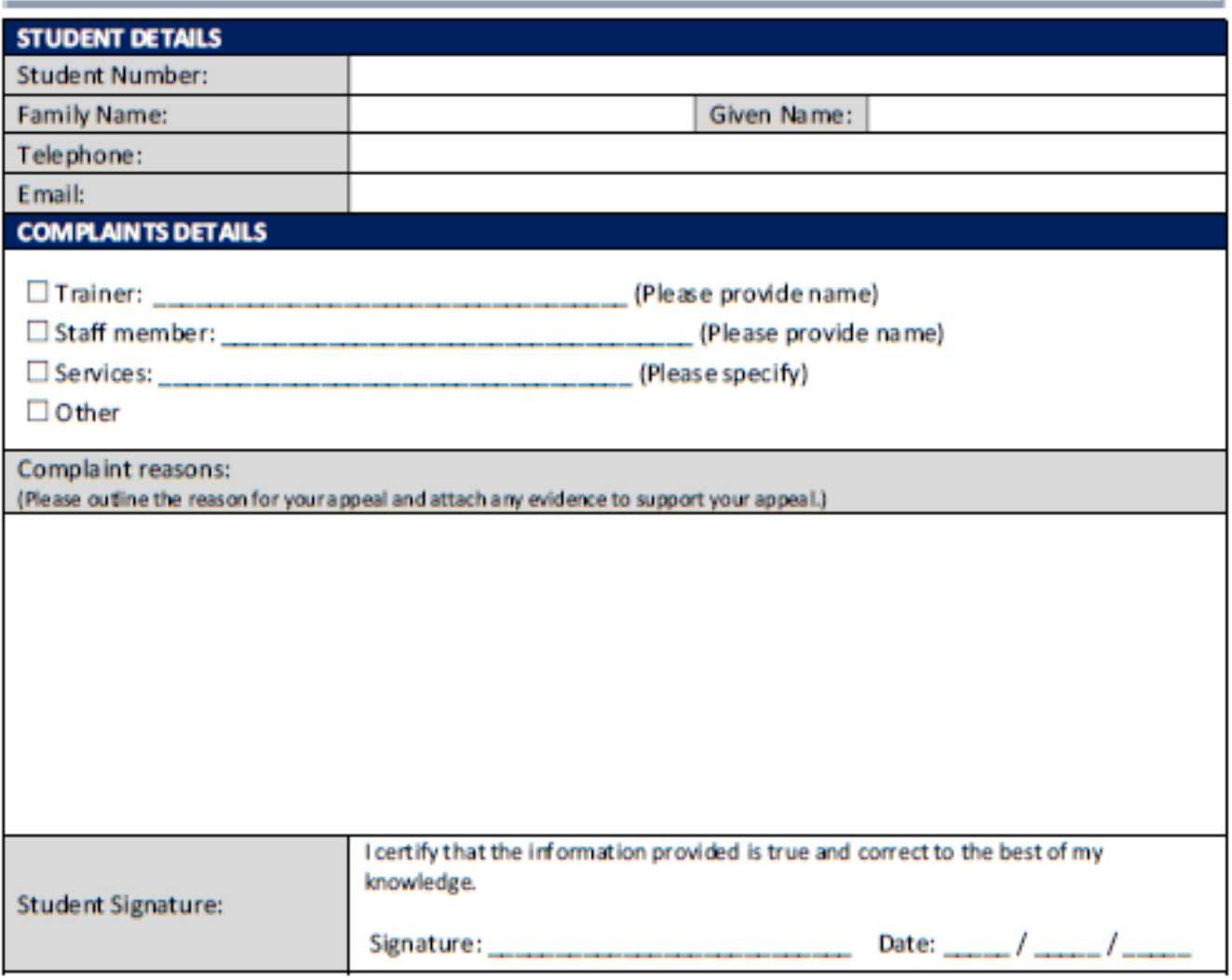

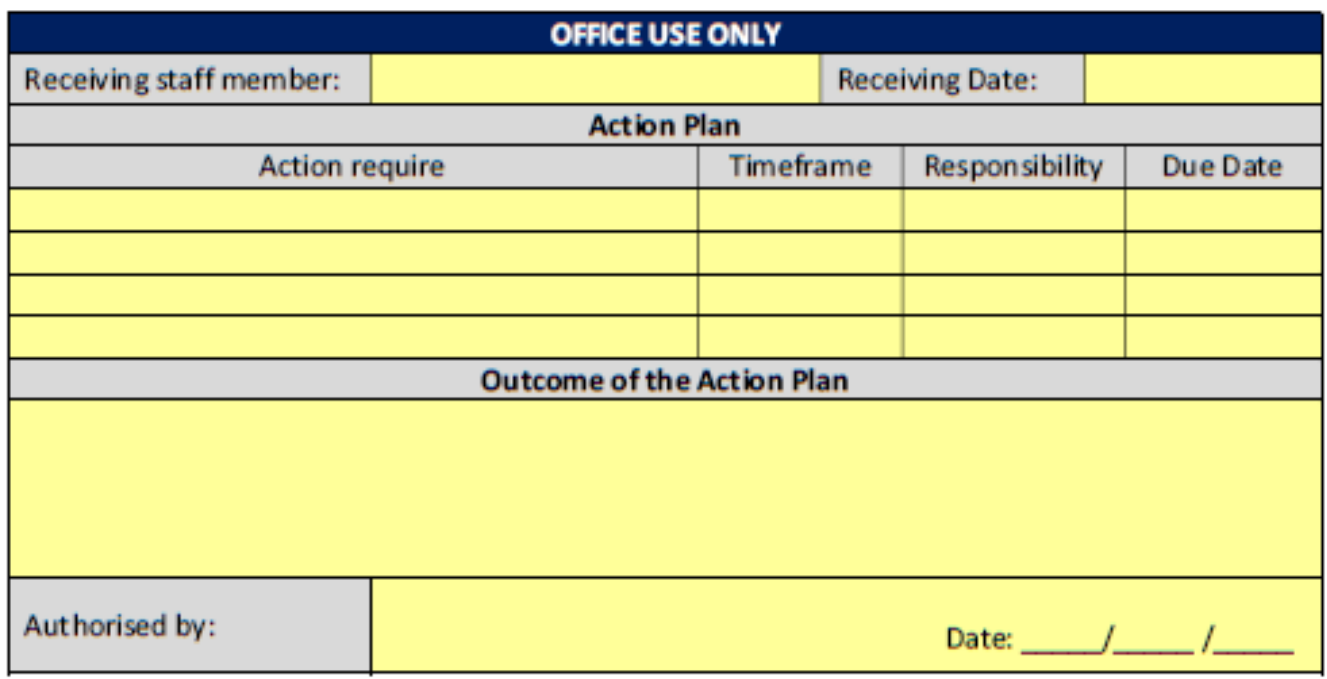

\section{Copyrights}

Copyright for this article is retained by the author(s), with first publication rights granted to the journal.

This is an open-access article distributed under the terms and conditions of the Creative Commons Attribution license (http://creativecommons.org/licenses/by/4.0/). 